\title{
Meta-analysis of functional neuroimaging studies indicates that an increase of cognitive difficulty during executive tasks engages brain regions associated with time perception.
}

\author{
Authors: Joaquim Radua ${ }^{a, e}$, Natalia Ojeda del Pozo b, José Gómez c, \\ Francisco Guilen-Grima ${ }^{d}$, Felipe Ortuño c, ${ }^{*}$ \\ a Department of Psychosis Studies. Institute of Psychiatry. King's College London. \\ b Department of Methods and Experimental Psychology. University of Deusto (Vizcaya, Spain) \\ c Department of Psychiatry. Clínica Universidad de Navarra. University of Navarre (Spain) \\ d Department of Preventive Medicine. Clínica Universidad de Navarra. University of Navarre \\ (Spain) \\ e FIDMAG Germanes Hospitalàries. Centro de Investigación Biomédica en Red de Salud \\ Mental (CIBERSAM, Spain) \\ *Corresponding author. E-mail address: fortunos@unav.es
}

\section{Abstract: \\ Objectives:}

We hypothesize that time perception and executive functions are interrelated and share neuroanatomical basis, and that fluctuations in levels of cognitive effort play a role in mediating that relation. The main goal of this study was to identify brain structures activated both by increases in cognitive activity and during time perception tasks.

\section{Methods:}

We performed a multimodal meta-analysis to identify common brain regions in the findings of (a) an SDM meta-analysis of neuroimaging studies assessing the brain response to increasing levels of cognitive difficulty, and (b) an ALE meta-analysis on neuroimaging of time perception (Ortuño et al. 2011).

\section{Results and conclusions:}

Consistent with results of previous, separate meta-analyses, the current study supports the hypothesis that there exists a group of brain regions engaged both in time perception tasks and during tasks requiring cognitive effort. Thus, brain regions associated with working memory and executive functions were found to be engaged during time estimation tasks, and regions associated with time perception were found to be engaged by an increase in the difficulty of non-temporal tasks. The implication is that temporal perception and cognitive processes demanding cognitive control become interlinked when there is an increase in the level of cognitive effort demanded. 


\section{Introduction}

According to the original Scalar Expectancy Theory (SET), time perception is attributable to the operation of three mental stages: clock processes, working (i.e. transitory) memory, and decision stages of the system (Treisman 1963; Treisman et al., 1990, Gibbon 1977; Matell et al., 2004). The theory holds that reference (i.e. lasting) memory contains a distribution of clock readings, and that this distribution is the source of scalar variability (Gibbon et al., 1984). According to this account, individual and pathophysiological differences in time perception might be attributable to alterations in the function of clock (e.g. pacemaker speed), working memory (e.g. encoding and decoding) or executive decision (e.g. response rule or bias) stages of the system (Meck, 2005, Allman and Meck, 2012).

Regarding the relationship between the neural mechanisms of time perception and other functions, studies on the prefrontal cortex evidence the implication of the same dorsolateral prefrontal cells for both cognitive timing and working memory (Constantinidis et al., 2002). Also, the neural mechanisms of timing are recruited in a manner that is modulated by degree of attention (Nobre and O'Reilly, 2004). Therefore, there is reason to postulate that correct executive functioning and cognitive control requires participation of functional and neuroanatomical components of time perception. In fact, time perception and other executive components such as interference control, seem to share a common neuroanatomical basis in early developmental stages (Neufang et al, 2008).

An additional aspect of every cognitive process, independent of the nature of that process (i.e., whether it is time perception or an executive function), is cognitive effort. Cognitive effort can be defined as the level of perceived difficulty of the cognitive task and the subsequent mental effort that the individual applies to achieve the cognitive aim. A typical task of normal everyday human activity may have not just one but various levels of cognitive difficulty. Therefore, many neuroimaging studies compare multiple (usually two) levels of difficulty of a given task, aiming not only to isolate brain regions responsible for the specific function that the task was designed to measure but 
also to compare variations based on the level of cognitive effort (Libby and Ragland, 2012).

In the last decade, neuroimaging studies in this field have focused on microanalysis of specific and independent brain networks related to each of the three SET subcomponents (Wencil et al, 2010).

Other studies have attempted to examine if different subtypes of time perception tasks are related with specific different patterns of regional brain activation, and their conclusions are still open to debate. For example, Macar and coworkers (Macar et al, 2002) show that characteristics specific to timing tasks (such as, perceptual vs. motor timing) do not affect the basic pattern of activations. On the other hand, the review by Lewis and Miall (2003) points out that participation of cerebral regions differs between studies according to whether the temporal processing taks applied by the study were automatic or controlled.

There have also been some attempts to identify the functional regions active specifically during time perception processing and not during other cognitive processes such as working memory or executive functioning (Livesey et al., 2007). These latter studies have not taken into account any possible effect of cognitive effort. Besides dissecting the anatomical basis of SET components in isolation of each other and attempting to eliminate the inherent effect of cognitive difficulty during performance, it is also of interest to analyze, at least qualitatively, the interrelationship between the theoretically separate cognitive functions of time perception, executive functions and working memory (Wearden 2013). Are there any brain regions involved simultaneously in all these functions? If so, what is the basis of their cooperation?.

We hypothesize that the neuroanatomical basis of time perception and executive functions are highly shared and interrelated, and that changes in levels of cognitive effort modify the relationship.

In order to test this hypothesis, the main goal of this study was to identify any structures activated both by increases in cognitive effort (e.g. while executing a working memory task with two levels of difficulty) and during time perception tasks. To this end, we undertook a multimodal meta-analysis to identify any possible common features in the findings of (a) an SDM meta-analysis of neuroimaging studies assessing the brain response to different levels of 
cognitive difficulty, and (b) an ALE meta-analysis on neuroimaging of time perception, which our neuroimaging team had previously published (Ortuño et al. 2011). Results are compared with those of studies of time perception (Lewis and Miall 2003; Wiener et al., 2010) and with those of studies of working memory and executive functions (Buchsbaum et al., 2005; Simmonds et al. 2008; Houdé et al. 2010; Kim et al. 2012; Niendam et al. 2012; Borst and Andreson 2013).

\section{Methods}

Meta-analysis of cognitive difficulty

A search at ISI Web of Science was carried out up to December 2012 using the keywords "PET" and "fMRI" cross-referenced with "working memory OR executive functions OR controlled processes".

We selected every functional neuroimaging study that included either a standardized cognitive task (i.e., WCST, CPT, Sternberg), or a specifically designed experimental activation task requiring cognitive processing. We then added a criterion concerning task difficulty: studies had to specify at least two separate levels of difficulty in the cognitive task. This requirement was needed because we wanted to investigate changes in brain activation patterns associated with changes in cognitive control and effort.

Methodological exclusion criteria were a) studies from which peak coordinates or parametric maps could not be retrieved from the published article or after contacting the authors; b) studies limiting their analyses to specific regions of interest (ROI); and c) studies in which different thresholds were used in different regions of the brain. The latter criterion was applied to avoid any bias towards brain regions that researchers had liberally thresholded (Radua and MataixCols 2009). MOOSE guidelines for meta-analyses of observational studies in epidemiology were followed (Stroup et al. 2000).

Figure 1 shows the flow diagram of the studies included in the present multimodal meta-analysis 
(Figure 1 about here)

A database was created with the MNI or Tailarach peak coordinates, their t- or p-values, and the number of participants included in each of the selected papers. These data were spatially summarized with a quantitative voxel-based meta-analysis by means of effect-size signed differential mapping software (ESSDM, http://www.sdmproject.com/) (Radua and Mataix-Cols 2009; Radua et al. 2011), a method which has already been applied to meta-analyze several brain functions (Hart et al. 2012; Hart et al. 2012). Voxel-based meta-analytic methods have been described in detail elsewhere (Radua and Mataix-Cols 2012), and only the specific main points of ES-SDM are summarized here.

First, Talairach-converted peak coordinates and their t-values were used to recreate an effect-size map of the BOLD response for each study. These maps included both activations (easy > difficult) and deactivations (difficult > easy) in order to avoid situations where BOLD response might appear simultaneously increased and decreased (Radua and Mataix-Cols 2010). We also calculated a separate effect-size variance for each study (Hedges and Olkin 1985; Radua, et al. 2011). Then, the effect-size maps and the effect-size variance maps of all studies were introduced into a meta-analytical random-effects model. In these models, the weight of each study in each voxel depends on the effect-size variance (which in turn depends on the intra-study variability in the voxel and on sample-size), and on the DerSimonian-Laird estimated between-study heterogeneity in the voxel (DerSimonian and Laird 1986; Radua et al. 2011). Finally, assessment of statistical significance was based on a distribution-free permutation test (Radua et al. 2011). This test, similar to that of new versions of ALE (Eickhoff et al. 2009), involves randomly permuting the location of voxels in the individual studies, following the null hypothesis that BOLD response is the same throughout all the brain, i.e. there are no specific brain regions linked to cognitive difficulty. We conducted 50 whole-brain permutations, corresponding to $3,892,500$ permuted meta-analytic voxel effect-sizes.

\section{Multimodal meta-analysis of cognitive difficulty and time perception}

Next, we performed a multimodal meta-analysis to combine the findings from the above-described SDM meta-analysis of studies comparing two levels of 
cognitive difficulty with the findings from an ALE meta-analysis on 35 neuroimaging studies exploring different aspects of time perception temporal discrimination, (supplementary data). This latter meta-analysis was previously published by our team (Ortuño et al. 2011), and its search was based on the following keywords: PET, fMRI cross-referenced with time estimation, timing, OR time perception, OR time estimation. Inclusion / exclusion criteria in the two meta-analyses were identical (Table 1).

\section{(Table 1 about here)}

Note that the aim of this multimodal analysis was not to detect correlations between the neural substrates of cognitive difficulty and time perception but rather to detect those brain regions which are activated or deactivated by both cognitive difficulty and time perception. In other words, essentially we overlapped the map of the BOLD response to cognitive difficulty with the map of the BOLD response to time perception. However, this was conducted using (a modification of the probability of the union of the maps (Radua et al. 2013), rather than a simple overlap of them, as the former has been shown to deal with the presence of error in the p-values of the individual meta-analyses whilst the latter does not. As recommended by Radua et al. (2013), a liberal threshold was first applied to the $p$-value maps obtained in the ALE and SDM meta-analyses (ALE-time: voxel FDR < 0.2; SDM: voxel $p<0.1$ uncorrected). The combination of the ALE and the SDM meta-analyses was then computed as the union of their probabilities (Radua et al. 2012). Final results were thresholded with voxel $p<0.01$, peak $p<0.001$, and cluster extent $\geq 10$ voxels.

\section{Results}

Our initial search returned several thousand papers. Subsequent application of inclusion criteria (Figure 1) reduced this number to the 54 papers detailed in Table 2. Of these, 28 studied executive function by means of standard tasks (such as N-back, Sternberg, WCST) whilst the remaining 26 used tasks of 
experimental design. All studies complied with the task difficulty criterion, that is, they compared two levels of task difficulty.

(Table 2 about here)

The results of the multimodal meta-analysis (Table 3) suggest a high degree of bilateral overlapping of cortical regions: specifically prefrontal and cingulate areas (mainly Brodmann area (BA) 6, but also BA 8, 9, 10, 24, 32, 44, 45, 46, 47), as well as parietal (BA 5,7,19, 39, 40) and temporal regions (BA 41, 13, and the claustrum).

(Table 3 about here)

Certain brain regions traditionally associated with time perception, most notably the insula (BA 13) and the left putamen, were found to be activated not only by time perception tasks but also by an increase in the difficulty of non-temporal executive functions.

As shown in Figure 2, together with the wide overlapping of frontal, cingulate, parietal, insular and putamen regions during time perception tasks and during tasks requiring cognitive effort, a statistically significant activation was found in a less extensive group of non-overlapping regions. The basal ganglia and the middle / superior temporal cortex were specifically activated only in time perception tasks (ALE meta-analysis), whereas the cerebellum and surrounding areas were activated during tasks requiring cognitive effort (SDM metaanalysis) (Figure 3 and Table 4).

(Figures 2 and 3 and Table 4 about here)

To check whether the main activated regions found in the multi-modal metaanalysis could be attributed the specific type of timing task, we calculated the proportion of studies reporting activation peaks close to the frontal and parietal peaks of the meta-analysis. As shown in Figure 4, the proportion of studies reporting one or more peaks close to the meta-analytic peaks was similar for studies requiring an auditory discrimination of duration, studies requiring a 
visual discrimination of duration, and a more heterogenous group of studies involving other timing tasks.

(Figure 4 about here)

\section{Discussion}

Globally, our results support the hypothesized existence of a group of brain regions engaged both during time perception tasks and during tasks requiring cognitive effort. Findings are consistent with a fMRI study which examined the effect of task difficulty on neuronal activation and the involvement of the dorsolateral prefrontal cortex (DLPFC) in timing (Tregellas et al., 2006). This work concluded that activation of several cortical (supplementary motor area, insula/operculum, DLPFC) and subcortical regions (thalamus and striatum) during timing tasks is load-dependent. Additionally, they observed activation of the dorsolateral prefrontal cortex under conditions of minimal working memory involvement. These finding support the specific involvement of this region in temporal processing rather than a more general involvement in working memory.

An alternative explanation is possible for part of our findings: the overlap between regions participating in both time perception and executive functions could also indicate that both functions require similar cognitive abilities, such as, sustained attention over time, maintaining information in working memory and taking decisions and preparing motor responses. However, our findings are also consistent with results from two previous meta-analyses carried out independently to explore the neuroanatomical basis of time perception and cognitive load (Lewis and Miall 2003; Niendam et al. 2012). On the one hand, activation on prefrontal (dorsolateral and ventrolateral), anterior cingulate, and parietal cortices is in agreement with the previous meta-analysis of 34 time perception studies by Lewis and Miall (2003). It also supports previous findings in studies of cognitively controlled timing (Mangels $\mathrm{J}$ et al. 1998; Rao et al. 2001; Pouthas et al. 2005). On the other hand, our data also replicate the pattern of activation observed by Niendam et al. (2012) in a meta-analysis involving the prefrontal, dorsal anterior cingulate, and parietal cortices across 
executive function domains. Niendam et al. suggested the existence of a superordinate cognitive control network that subserves a broad range of executive functions (planning, goal setting, flexibility, vigilance or working memory among others).

As in Wiener's meta-analysis (2010), the current study detected activation of BA 6, which includes the supplementary motor cortex (SMA), during perception of time; BA 6 was, overall, the brain region with the largest activation in terms of voxels. Despite the cognitive nature of the task evaluated and its level of difficulty, Wiener et al. (2010) reported that, the SMA, together with the inferior frontal gyrus, was an area involved in time perception. Also, significant increases of activation in the SMA during high-effort cognitive tasks were reported in a recent review by Hanakawa et al. (2008). The authors concluded that BA 6 may be activated on demand during the implementation of several cognitive tasks, such as, mental arithmetic, spatial and non-spatial working memory, attention control, silent word production and conceptual reasoning (Hanakawa et al., 2008).

Our study found the bilateral insula, the left inferior parietal (supramarginal gyrus) and the putamen to be engaged during time perception tasks. This is in agreement with Livesey et al.'s data (2007) and provides further evidence of the participation of these regions in time perception and specifically with tasks of internal time perception independently of the level of difficulty of the task (Livesey et al 2007). Over the last few years, and in accordance with the striatal beat frequency (SBF) model, the putamen has come to be regarded as having greater specific relevance during time perception tasks (Matell and Meck, 2004). In the SBF model, the 'internal clock' crucially depends on striatal integration of oscillating cortical activity. Tsukamoto et al. (2006) reported the activation of the insular cortex and putamen, among other subcortical regions, in their time estimation task experiments and suggested an influence of motivational factors in the participation of these regions. However, according to Sterzer et al., (2010) the activation of the insular cortex occurs during diverse cognitive tasks that demand real or perceived effort. According to Livesey et al.'s findings, the bilateral insula, the left putamen and the inferior parietal regions are also engaged by an increased cognitive load during various nontemporal tasks. Furthermore, in Niendam et al.'s combined meta-analysis, 
these three regions were significantly activated by various cognitive steps of executive functions.

Our results also reproduce the psychophysiological interaction patterns reported by Neufang et al. (2008), who described a fronto-parietal-cerebellar network neural activation pattern associated with both time perception and cognitive control (interference control). We found a comparable pattern shared by both process types but which included not only the bilateral frontal and parietal cortices but also the insula and left putamen.

As in Niendam et al.'s meta-analysis, we found additional concurrent regions of activation during cognitive studies on subcortical areas including the thalamus and cerebellum. As in Livesey's study, we saw, during time perception tasks, participation of the putamen and the absence of participation of the thalamus ; however, we did not detect implication of the cerebellum, which Livesey's study did.

Therefore, our findings regarding overlapping of subcortical activation between cognitive control and time perception tasks approximate those of Niendam's meta-anlaysis of executive function domains and those of Liveseley's time perception study. Our findings suggest that the cerebellum is specifically implicated by tasks involving cognitive activation but not by tasks of temporal perception. Activation of the cerebellum has been reported in several, but not all, previous studies of neuroimaging of time perception (Ivry et al., 2002). According to the studies of Lewis and Miall $(2003,2006)$, the participation of the cerebellum in time perception tasks is related to timing tasks that are automatic (rather than controlled).

The studies included in our meta-analysis, in accordance with our inclusion criteria, compare two levels of difficulty in timing tasks. Thus, these studies are concerned, fundamentally, with examining timing processes that are controlled (as opposed to automatic). In this sense, our finding of an absence of participation of the cerebellum in time perception studies is in agreement with the interpretation of Lewis and Miall.

Finally, there are two other specific regions that our meta-analysis indicated, although with a less significant number of voxels, to be engaged by both time perception and executive functions: the occipital cortex (BA 19) and the 
claustrum. Engagement of the occipital cortex, which was bilateral, is perhaps related to the fact that visual cognitive stimuli were commonly used by design in the studies in both of our groups. A similar occipital activation pattern was described by Niendam (2012) in an ALE meta-analysis of various dimensions of executive functions. Engagement of the claustrum was also reported by Wiener et al. (2010) and Niendam et al. (2012) in their meta-analyses concerning time perception and cognitive control, respectively.

Most of the activation patterns identified in our study were bilateral, whilst previous studies have been suggestive of a predominantly right-side pattern in prefrontal and parietal regions during time perception (Coull and Nobre, 1998; Coull et al., 2004; Maquet et al., 1996; Pouthas et al., 2005; Smith et al., 2003; Ortuño et al., 2010).

Our results are in agreement with the classic patterns of activation during various executive functioning tasks. Specifically, we found a pattern of frontoparietal-insula and putamen activation common to both studies of executive functioning and studies of time perception. This adds support in favour of the hypothesis of a potential common cognitive network involved during both cognitive processes. An alternative explanation for these commonalties would still be possible: that both functions require similar cognitive abilities, such as, sustained attention over time, keeping information in working memory and taking decisions and preparing motor responses. However, other cognitive processes such as learning, memory and retrieval also require temporal components, and the same commonalties have not been identified with these latter processes.

We suggest that during time perception tasks there is participation of various cognitive processes (such as working memory or executive functions). In a parallel manner, we argue that during non-temporal cognitive tasks with various levels of cognitive effort, some level of temporal processing is needed and engaged. Therefore, brain regions traditionally associated with working memory and executive functions (i.e., the prefrontal cortex and fronto-parietal regions) would be engaged during time estimation tasks. But also, specific regions traditionally associated with time perception (such as the insula and the putamen) would be engaged during non-temporal cognitive tasks in response to increases in the level of difficulty. Livesey et al. (2007), based on the results of 
reversing the relative difficulty of tasks of time perception and cognitive control, suggested that the sign of the differential activation in the brain areas involved can reverse itself, and so activity in these regions is not related specifically to judging time and the perception of time, but rather to cognitive effort or task difficulty.

Functional neuroimaging studies often find certain brain regions to be engaged during apparently unrelated cognitive tasks, such as, temporal perception and processes requiring cognitive control. The results presented here suggest that the missing link between the brain regions engaged and the cognitive tasks in these various studies is the level of cognitive control/effort. In particular, the meta-analysis shows that specific brain regions traditionally associated with time perception are significantly more active with relatively difficult non-temporal cognitive tasks than they are with easier versions of the same tasks. 


\section{References}

\section{References}

1. Allman, M.J., Meck W. H., 2012. Pathophysiological distortions in time perception and timed performance. Brain 135(3), 656-677.

2. Anderson, E. J., Mannan, S. K., Rees, G., Kennard, Sumner, P., Kennard, C., 2010. Overlapping functional anatomy for working memory and visual search. Exp Brain Res. 200, 91-107.

3. Anilkumar, A. P. P., Kumari, V., Mehrotra, R., Aasen, I., Mitterschiffthaler, M. T., Sharma, T., 2008. An fMRI study of face encoding and recognition in first-episode schizophrenia. Acta Neuropsychiatrica 20, 129-138.

4. Barbalat, G., Chambon, V., Franck, N., Koechlin, E., Farrer, C., 2009. Organization of cognitive control within the lateral prefrontal cortex in schizophrenia. Archives of general psychiatry 66(4), 377-86.

5. Bleich-Cohen, M., Hendler, T., Kotler, M., Strous, R. D., 2009. Reduced language lateralization in first-episode schizophrenia: an fMRI index of functional asymmetry. Psychiatry research 171(2), 82-93.

6. Bonner-Jackson, A., Yodkovik, N., Csernansky, J. G., Barch, D. M., 2008. Episodic memory in schizophrenia: the influence of strategy use on behavior and brain activation. Psychiatry research 164(1), 1-15.

7. Borofsky, L. A., McNealy, K., Siddarth, P., Wu, K. N., Dapretto, M., Caplan, R., 2010. Semantic processing and thought disorder in childhood-onset schizophrenia: Insights from fMRI. Journal of Neurolinguistics 23, 204-222

8. Borst-Jelmer, P., Andreson, J.R., 2013. Using model-based functional MRI to locate working memory updates and declarative memory retrievals in the fronto-parietal network. PNAS 110, 1628-1633.

9. Brahmbhatt, S. B., Mcauley, T., Barch, D. M., 2008. Functional developmental similarities and differences in the neural correlates of verbal and nonverbal working memory tasks. Neuropsychologia 46, 1020-1031.

10. Broome, M. R., Matthiasson, P., Woolley, J. B., Valmaggia, L., Johns, L. C., 2009. Neural correlates of visuospatial working memory in the " at-risk mental state ". The British Journal of Psychiatry 194, 25-33.

11.Buchsbaum, B.R., Greer, S., Chang, W.L., Berman, K.F., 2005. Metaanalysis of neuroimaging studies of the Wisconsin card-sorting task and component processes. Hum. Brain Mapp. 25, 35- 45.

12. Camchong, J., Dyckman, K., Austin, B. P., Clementz, B., McDowell, J. E., 2008. Common neural circuitry supporting volitional saccades and its disruption in schizophrenia patients and relatives. Biological psychiatry 64(12), 1042-50. 
13. Champod, A. S., Petrides, M., 2010. Dissociation within the Frontoparietal Network in Verbal Working Memory: A Parametric Functional Magnetic Resonance Imaging Study. The Journal of Neuroscience 30(10), 3849 3856.

14. Choi, J. W., Jeong, B. S., Kim, J.W., 2008). Dysfunction of the Left Dorsolateral Prefrontal Cortex is Primarily Responsible for Impaired Attentional Processing in Schizophrenia. Psychiatry Invest 5, 52-59

15. Christoff, K., Keramatian, K., Gordon, A. M., Smith, R., Mädler, B., 2009. Prefrontal organization of cognitive control according to levels of abstraction. Brain Research 1286, 94-105.

16. Coull, J.T., Nobre, A.C., 1998. Where and when to pay attention: The neural systems for directing attention to spatial locations and to time intervals as revealed by both PET and fMRI. J. Neurosci. 18, 7426- 7435.

17. Coull, J.T., Vidal,F., Nazarian, B., Macar,F., 2004. Functional anatomy of the attentional modulation of time estimation. Science 303,1506 - 1508.

18. Constantinidis C1, Williams GV, Goldman-Rakic PS. A role for inhibition in shaping the temporal flow of information in prefrontal cortex. Nat Neurosci. 2002 Feb;5(2):175-80

19. Crossley, N.A., Mechelli, A., Fusar-Poli, P., Broome, M.R., Matthiasson, P., Johns, L.C., Bramon, E., Valmaggia, L., Williams, S. C. R., McGuire, P. K., 2009. Superior Temporal Lobe Dysfunction and Frontotemporal Dysconnectivity in Subjects at Risk of Psychosis and in First-Episode Psychosis. Human Brain Mapp. 30, 4129-4137

20.DerSimonian, R. and N. Laird (1986). "Meta-analysis in clinical trials." Control Clin Trials 7(3): 177-188.

21. Eickhoff SB, Laird AR, Grefkes C, Wang LE, Zilles K, Fox PT. (2009). Coordinate-based activation likelihood estimation meta-analysis of neuroimaging data: a random-effects approach based on empirical estimates of spatial uncertainty. Hum Brain Mapp 30(9): 2907-2926.

22. Eslinger, P. J., Blair, C., Wang, J., Lipovsky, B., Realmuto, J., Baker, D., Thorne, S., Gamson, D., Zimmerman, E., Rohrer, L., Yang, Q. X., 2009. Brain and Cognition Developmental shifts in fMRI activations during visuospatial relational reasoning. Brain and Cognition 69(1), 1-10.

23. Forn, C., Ventura-Campos, N., Belenguer, A., Belloch, V., Parcet, M.A., Avila, C., 2008. A Comparison of Brain Activation Patterns During Covert and Overt Paced Auditory Serial Addition Test Tasks. Human Brain Mapping $29,644-650$

24. Fusar-poli, P., Broome, M. R., Matthiasson, P., Woolley, J. B., Johns, L. C., Tabraham, P., 2010. Spatial working memory in individuals at high risk for psychosis: Longitudinal fMRI study. Schizophrenia Research 123(1), 45-52.

25. Gibbon, J., 1977. Scalar expectancy theory and Weber's law in animal timing. Psychol. Rev. 84, 279-325. 
26. Gibbon, J., Church, R. M., Meck, W., 1984. Scalar timing in memory, in: Gibbon J., Allan, L. (Eds.), Ann. N. Y. Acad. Sci., 423: Timing and time perception (pp. 52-77). New York: New York Academy of Sciences.

27. Green, M. F., Lee, J., Cohen, M. S., Engel, S., Korb, A. S., Nuechterlein, K. H., Wynn, J. K., Glahn, D. C.,2009. Functional neuroanatomy of visual masking deficits in schizophrenia. Archives of general psychiatry 66(12), 1295-303.

28. Hampshire, A., Thompson, R., Duncan, J., Owen, A. M., 2009. Selective tuning of the right inferior frontal gyrus during target detection. Cognitive, Affective, and Behavioral Neuroscience 9 (1), 103-112

29. Hanakawa, T., Dimyan, M.A., Hallett, M., 2008. Motor planning, imagery, and execution in the distributed motor network: a time-course study with functional MRI. Cereb. Cortex 18 (12), 2775-2788.

30. Hart, H., Radua, J., Nakao, T, Mataix-Cols, D, Rubia K., 2012. Meta-analysis of Functional Magnetic Resonance Imaging Studies of Inhibition and Attention in Attention-deficit/Hyperactivity Disorder: Exploring Task-Specific, Stimulant Medication, and Age Effects. JAMA Psychiatry 70 (2), 185-198.

31. Hart, H., Radua, J., Mataix-Cols, D, Rubia, K., 2012. Meta-analysis of fMRI studies of timing in attention-deficit hyperactivity disorder (ADHD). Neurosci. Biobehav. Rev. 36 (10), 2248-56.

32. Hashimoto, R., Lee, K., Preus, A., McCarleyand, R. W., Wible, C. G., 2010. An fMRI Study of Functional Abnormalities in the Verbal Working Memory System and the Relationship to Clinical Symptoms in Chronic Schizophrenia. Cerebral Cortex 20, 46-60.

33. Hedges, L. V. and I. Olkin (1985). Statistical Methods for Meta-Analysis. Orlando, Academic Press.

34. Henseler, I, Falkai, P., Gruber, O., 2009. A systematic fMRI investigation of the brain systems subserving different working memory components in schizophrenia. Cognitive neuroscience 30, 693-702.

35. Hirano, Y., Obata, T., Kashikura, K., Nonaka, H., 2008. Effects of chewing in working memory processing. Neuroscience Letters 436, 189-192.

36. Houdé, O., Rossi, S., Lubin, A., Joliot, M., 2010. Mapping numerical processing, reading, and executive functions in the developing brain: an fMRI meta-analysis of 52 studies including 842 children. Developmental Science 13, 876-885

37. Ikeda, Y., Yahata, N., Takahashi, H., Koeda, M., Asai, K., Okubo, Y., Suzuki, $\mathrm{H} ., 2010$. Cerebral activation associated with speech sound discrimination during the diotic listening task: An fMRI study. Neuroscience Research 67(1), 65-71.

38. Ivry, R.B., Spencer, R.M., Zelaznik, H.N., Diedrichsen, J., 2002. The cerebellum and event timing. Ann. N. Y. Acad. Sci. 978, 302-317. 
39. Ivry, R., Spencer, R., 2004. The neural representation of time. Curr. Opin. Neurobiol. 14, 225-32.

40.Jamadar, S., Michie, P., Karayanidis, F., 2010. Neuropsychologia Compensatory mechanisms underlie intact task-switching performance in schizophrenia. Neuropsychologia 48(5), 1305-1323.

41. Karlsgodt, K. H., Sanz, J., Erp, T. G. M. V., Bearden, C. E., Nuechterlein, K. H., Cannon, T. D., 2009. Re-evaluating dorsolateral prefrontal cortex activation during working memory in schizophrenia. Schizophrenia Research 108(1-3), 143-150.

42. Kim J, Matthews NL, Park S., 2010. An Event-Related fMRI Study of Phonological Verbal Working Memory in Schizophrenia. PLoS ONE 5(8), e12068.

43.Kim, k.K., Eliassen, J.C., Lee, S.K., Kang, E., 2012. Functional neuroanatomy of visual search with differential attentional demands: An fMRI study. Brain Res. 1475, 49-61

44. Kirschen, M. P., Chen, S. H. A., Desmond, J. E., 2010. Modality specific cerebro-cerebellar activations in verbal working memory: An fMRI study. Behavioural Neurology 23, 51-63.

45. Koch, Kathrin, Schachtzabel, C., Wagner, G., Schikora, J., Schultz, C., Reichenbach, J. R., Sauer, H., Schlösser, R. G. M., 2010. Altered activation in association with reward-related trial-and-error learning in patients with schizophrenia. Neurolmage 50(1), 223-232.

46. Landau, S. M., Lal, R., O’Neil, J. P., Baker, S., Jagust, W. J., Berkeley, L., 2009. Striatal Dopamine and Working Memory. Cerebral Cortex 19, 445454.

47. Leshikar, E. D., Gutchess, A. H., Hebrank, A. C., Sutton, B. P., Park, D. C., 2010. The impact of increased relational encoding demands on frontal and hippocampal function in older adults. Cortex 46(4), 507-521.

48. Lewandowska, M., Piatkowska-janko, E., Bogorodzki, P., Wolak, T., Szelag, E., 2010. Neurobiology of Learning and Memory Changes in fMRI BOLD response to increasing and decreasing task difficulty during auditory perception of temporal order. Neurobiology of Learning and Memory 94(3), 382-391.

49. Lewis, P.A., Miall, R.C., 2003. Distinct systems for automatic and cognitively controlled time measurement: evidence from neuroimaging. Curr. Opin. Neurobiol. 13, 250-255.

50. Lewis, P.A., Miall, R.C., 2006. Remembering the time: a continuous clock. Trends in Cognitive Sciences Vol.10 No.9 50. Li, J., Liu, J., Liang, J.,

51. Libby, L.A., Ragland, J.D., 2012. fMRI as a measure of cognition related brain circuitry in schizophenia. Topics Behav. Neurosci. 11, 253-267. 
52. Livesey, A.C., Wall, M.B., Smith, A.T., 2007. Time perception: Manipulation of task difficulty dissociates clock functions from other cognitive demands. Neuropsychologia 45, 321- 331

53.Luck, D., Danion, J. M., Marrer, C., Pham, B. T., Gounot, D., Foucher, J., 2010. Abnormal Medial Temporal Activity for Bound Information During Working Memory Maintenance in Patients With Schizophrenia. Hippocampus 20, 936-948

54. Macar, F., Lejeune, H., Bonnet M., Ferrara, A., Pouthas V., Vidal, F, et al. 2002. 2002. Activation of the supplementary motor area and of attentional networks during temporal processing. Exp. Brain Res. 142 (4), 475-485.

55. Mangels, J.A., Ivry, R.B., Shimizu, N., 1998. Dissociable contributions of the prefrontal and neocerebellar cortex to time perception. Cog. Brain Res. 7, 15-39

56. Maquet, P., Lejeune, H., Pouthas, V., Bonnet, M., Casini, L., Macar, F., Timsit-Berthier, M., Vidal, F., Ferrara, A., Degueldre, C., Quaglia, L., Delfiore, G., Luxen, A., Woods, R., Mazziotta, J.C., Comar, D., 1996. Brain activation induced by estimation of duration: a PET study. Neuroimage 3, 119-126.

57. Matell, M.S., Meck, W.H., 2004. Cortico-striatal circuits and interval timing: coincidence detection of oscillatory processes. Brain Res. Cog. Brain Res. 21, 139-170.

58. Mathis, A., Schunck, T., Erb, G., Namer, I. Z., Luthringer, R., 2009. The effect of aging on the inhibitory function in middle-aged subjects: a functional MRI study coupled with a color-matched Stroop task. Int J Geriatr Psychiatry 24, 1062-1071.

59. Meck, W.H., 2005. Neuropsychology of timing and time perception. Brain Cognition 58, 1-8.

60.Neufang, S., Fink, G.R., Herpertz-Dahlmann, B., Willmes, K., Konrad, K., 2008. Developmental changes in neural activation and psychophysiological interaction patterns of brain regions associated with interference control and time perception. Neuroimage 43, $399-409$.

61. Niendam,T. A., Laird, A.R., Ray, K. L. ,. Dean,Y. M., Glahn, D.C. , Carter, C. S., 2012. Meta-analytic evidence for a superordinate cognitive control network subserving diverse executive functions. Cogn. Affect .Behav. Neurosci. 12, 241-268.

62. Nobre A.C., O'Reilly J., 2004. Time is of the essence. Trends in Cognitive Sciences Vol.8 No.9, 387-389.62.

63. O'Hare, E.D., Lu, L.H., Houston, S. M., Bookheimer, S.Y., Sowell, E. R., 2008. Neurodevelopmental changes in verbal working memory loaddependency: An fMRI investigation. Neurolmage 42, 1678-1685. 
64. Ortuño, F., Guillén-Grima F., López-García, P., Gómez, J., Pla, J., 2011. Functional neural networks of time perception: challenge and opportunity for schizophrenia research. Schizophr. Res. 125(2-3), 129-35.

65.64. Pouthas, V., George, N., Poline, J.B., Pfeuty, M., Vandemoorteele, P.F., Hugueville, L., Ferrandez, A.M., Lehericy, S., Lebihan, D., Renault, B., 2005. Neural network involved in time perception: an fMRI study comparing long and short interval estimation. Hum. Brain Mapp. 25, 433-441.

66. Rao, S.M., Mayer, A.R., Harrington, D.L., 2001. The evolution of brain activation during timing. Nat. Neurosci. 4, 317-323.

67. Radua, J., Borgwardt, S., Crescini, A., Mataix-Cols, D., Meyer-Lindenberg, A., McGuire, P.K., Fusar-Poli, P., 2012. Multimodal meta-analysis of structural and functional brain changes in first episode psychosis and the effects of antipsychotic medication. Neurosci. Biobehav. Rev. 36 (10), 232533.

68. Radua, J., Mataix-Cols, D., 2009. Voxel-wise meta-analysis of grey matter changes in obsessive-compulsive disorder. Br. J. Psychiatry 195 (5), 393402.

69. Radua, J. Mataix-Cols, D., 2010. Heterogeneity of coordinate-based metaanalyses of neuroimaging data: an example from studies in OCD Reply. Br. J. Psychiatry 197 (1), 77.

70. Radua, J., Mataix-Cols, D., 2012. Meta-analytic methods for neuroimaging data explained. Biol. Mood Anxiety Disord. 2, 6.

71. Radua, J., Mataix-Cols, D., Phillips, M.L., El-Hage, W., Kronhaus, D.M., Cardoner, N., Surguladze, S., 2011. A new meta-analytic method for neuroimaging studies that combines reported peak coordinates and statistical parametric maps. Eur. Psychiatry 27 (8), 605-11.

72. Radua, J., Romeo, M., Mataix-Cols, D., Fusar-Poli, P., 2013. A general approach for combining voxel-based meta-analyses conducted in different neuroimaging modalities. Curr. Med. Chem. 20 (3), 462-6.

73. Reynolds, J. R., West, R., Braver, T., 2009. Distinct Neural Circuits Support Transient and Sustained Processes in Prospective Memory and Working Memory. Cerebral Cortex 19, 1208-1221.

74. Rubia, K., Hyde, Z., Halari, R., Giampietro, V., Smith, A., 2010. Effects of age and sex on developmental neural networks of visual - spatial attention allocation. Neuroimage 51(2), 817-827.

75. Scheuerecker, J., Ufer, S., Käpernick, M., Wiesmann, M., Brückmann, H., Kraft, E., Seifert, D., Koutsouleris, N., Möller H.J., Meisenzahl, E.M., 2009. Cerebral network deficits in post-acute catatonic schizophrenic patients measured by fMRI. J. Psychiatr. Res. 43(6), 607-614.

76. Schlösser, R.G.M., Koch, K., Wagner, G., Nenadic, I., Roebel, M., Schachtzabel, C., Axer, M., 2008. Inefficient executive cognitive control in 
schizophrenia is preceded by altered functional activation during information encoding: An fMRI study. Neuropsychologia 46, 336-347.

77. Sharp, D. J., Awad, M., Warren, J. E., Wise, R. J. S., Vigliocco, G., Scott, S. K., 2010. The Neural Response to Changing Semantic and Perceptual Complexity During Language Processing. Human Brain Mapping 31, 365377.

78. Silk, T. J., Bellgrove, M. A., Wrafter, P., Mattingley, J. B., Cunnington, R., 2010. Spatial working memory and spatial attention rely on common neural processes in the intraparietal sulcus. Neuroimage 53(2), 718-724.

79. Simmonds, D.J., Pekar, J.J., Mostofsky, S.H., 2008. Meta-analysis of Go/No-go tasks demonstrating that fMRI activation associated with response inhibition is task-dependent. Neuropsychologia 46, 224-232.

80. Smith, A., Taylor, E., Lidzba, K., Rubia, K., 2003. A right hemispheric frontocerebellar network for time discrimination of several hundreds of milliseconds. Neuroimage 20, 344-350.

81. Specht, K., Lie, C., Shah, N. J., Fink, G. R., 2009. Disentangling the Prefrontal Network for Rule Selection By Means of a Non-Verbal Variant of the Wisconsin Card Sorting Test. Human Brain Mapping 30,1734-1743

82. Sterzer, P., Kleinschmidt, A., 2010. Anterior insula activations in perceptual paradigms: often observed but barely understood. Brain. Struct. Funct. 214, 611-622.

83. Stroup, D.F., Berlin, J.A., Morton, S.C., Olkin, I., Williamson, D., Rennie, D., Moher, D., Becker, B.J., Sip, T. A., Thacker, S. B. 2000. Meta-analysis of observational studies in epidemiology: a proposal for reporting. Metaanalysis Of Observational Studies in Epidemiology (MOOSE) group. JAMA 283(15), 2008-12.

84. Takahama, S., Miyauchi, S., Saiki, J., 2010. Neural basis for dynamic updating of object representation in visual working memory. Neuroimage 49(4), 3394-3403.

85. Thompson, R., Duncan, J., 2009. Attentional modulation of stimulus representation in human fronto-parietal cortex. Neuroimage 48(2), 436-448.

86. Toepper, M., Gebhardt, H., Beblo, T., Thomas, C., Driessen, M., Bischoff, M., Blecker, C. R., Vaitl, D., Sammer, G., 2010. Functional correlates of distractor suppression during spatial working memory encoding. Neuroscience 165, 1244-1253.

87. Tregellas,J.R., Davalos D.B., Rojas D.C. Effect of task difficulty on the functional anatomy of temporal processing. Neurolmage 32 (2006) 307 315

88. Treisman, M., 1963. Temporal discrimination and the indifference interval: Implications for a model of the "Internal Clock". Psychological Monographies 77, 13. 
89. Treisman, M, Faulkner, A, Naish, P., 1990. The internal clock - Evidence for a temporal oscillator underlying time perception with some estimates of its characteristic frequency. Perception 19(6), 705-743.

90. Tsukamoto, T., Kotani, Y., Ohgami, Y., Omura, K., Inoue, Y., Aihara, Y., 2006. Activation of insular and subcortical regions related to feedback stimuli in a time estimation task: an fMRI study. Neurosci. Lett. 399, 39-44.

91. Ungar, L., Nestor, P. G., Niznikiewicz, M.A., Wible, C. G., Kubicki, M., 2010. Color Stroop and negative priming in schizophrenia: An fMRI study. Psychiatry Research: Neuroimaging 181, 24-29

92. Usui, N., Haji, T., Maruyama, M., Katsuyama, N., Uchid, S., Hozawa, A., Omori, K., Tsuji, I., Kawashima, R., Taira, M., 2009. Cortical areas related to performance of WAIS Digit Symbol Test: A functional imaging study. Neuroscience Letters 463, 1-5

93. Vinogradov, S., Luks, T. L., Schulman, B. J., Simpson, G. V., 2008. Deficit in a Neural Correlate of Reality Monitoring in Schizophrenia Patients. Cerebral Cortex 18, 2532-2539

94. Vuontela, V., Steenari, M., Aronen, E. T., Korvenoja, A., Aronen, H. J., Carlson, S., 2009. Brain activation and deactivation during location and color working memory tasks in 11-13-year-old children. Brain and Cognition 69, 56-64

95. Van Veelen, N. M. J., Vink, M., Ramsey, N. F., Kahn, R.S., 2010. Left dorsolateral prefrontal cortex dysfunction in medication-naive schizophrenia Schizophrenia Research 123, 22-29.

96. Van Raalten, T. R., Ramsey, N. F., Jansma, J. M., Jager, G., Kahn, R. S., 2008. Automatization and working memory capacity in schizophrenia. Schizophrenia Research 100, 161-171.

97. Wendelken, C., Bunge, S. A., Carter, C.S., 2008. Maintaining structured information: An investigation into functions of parietal and lateral prefrontal cortices. Neuropsychologia 46, 665-678

98. Waiter, G. D., Deary, I. J., Staff, R.T., Murray, A. D., Fox, H. C., Starr, J. M., Whalley, L. J., 2009. Exploring possible neural mechanisms of intelligence differences using processing speed and working memory tasks: An fMRI study. Intelligence 37, 199-206

99. Wearden, J.H., 2013. The cognitive neuroscience of time perception: how psychological studies might help to dissect the timing system. Neuropsychologia 51(2),187-90.

100.Wencil, E.B., Coslett, B., Aguirre, G.K., Chatternejee, A., 2010. Carving the clock at its component joints: neural bases for interval timing. J. Neurophysiol. 104 (1), 160-168.

101. Wiener, M., Turkeltaub, P., Coslett, H.B., 2010. The image of time: a voxel-wise meta-analysis. Neuroimage 49(2), 1728-40. 
102.Zhang, H., Zhao, J., Huber, D. E., Rieth, C. A., Lee, K., Tian, J., Shi, G., 2009. Neuroscience Letters A distributed neural system for top-down face processing. Neuroscience Letters 451, 6-10. 


\section{FIGURE LEGENDS}

Figure 1. Flow diagram of the study selection process.

Figure 2. Brain regions engaged both during time perception tasks and during tasks requiring cognitive effort.

Footnote to Figure 2: Top and middle panels show the medial and lateral cortical regions activated both during time perception tasks and during tasks requiring cognitive effort. Bottom panel shows the same regions overlaid on Talairach axial slices in neurological convention (i.e. right is right, left is left). For illustration purposes, statistically significant degree of overlap was smoothed with a $\sigma=4 \mathrm{~mm}$ Gaussian kernel and ranges from 0.0 (black, no overlap) to 0.8 (yellowish / whitish tone).

Figure 3. Overlap and lack of overlap between brain regions engaged during time perception tasks and during tasks requiring cognitive effort.

Footnote to Figure 3: Talairach axial slices in neurological convention (i.e. right is right, left is left) showing regions with statistically significant activation only during time perception tasks (ALE meta-analysis, red), regions with statistically significant activation only during tasks requiring cognitive effort (SDM metaanalysis, blue), and regions with statistically significant activation both during time perception tasks and during tasks requiring cognitive effort (green). Note that for clarity, statistical parameters were slightly smoothed, and clusters comprising less than 100 voxels are not shown.

Figure 4. Proportion of timing tasks studies reporting peaks close to the metaanalytic peaks, separately by types of timing task. 
Footnote to Figure 4: Steps to consider peaks of the individual studies to be close to a meta-analytic peak were as follows: a) SDM pre-processing of the studies peak coordinates with a narrow kernel $(\mathrm{FWHM}=10 \mathrm{~mm})$ to obtain a map, for each study, of the proximity of any voxel to a study peak; b) extraction of the value of the voxels at the location of the meta-analytic peak; c) calculation of the proportion of studies with non-null values. 


\section{Table 1. Inclusion criteria for the selected studies}

Studies should have been published in a peer-review journal.

They should have used either fMRI or PET neuroimaging tools.

They should have reported the coordinates of maxima activation in a standardized stereotaxic space.

All brain areas should have been analyzed for activation, not just regions of interest.

Studies should have included at least one contrast between two different levels of difficulty of the cognitive task.

Studies could have been either conducted using standarized (e.g. WCST, CPT etc) or experimental design tasks. 
Table 2. Studies of cognitive activation included in our SDM meta-analysis

\begin{tabular}{|c|c|c|c|c|}
\hline Autor & $\begin{array}{l}\text { Neuroimaging } \\
\text { tool }\end{array}$ & $n$ & Task & Included contrast \\
\hline 1. Anderson E. J. (2010) & fMRI & 12 & $\begin{array}{l}\text { Spatial (SWM) and verbal (VWM) working } \\
\text { memory tasks* }\end{array}$ & SWM vs. spatial search alone \\
\hline 2. Brahmbhatt S.B. (2008) & fMRI & 78 & N-back & N-back vs. zero-back \\
\hline 3. Champod A.S. (2010) & fMRI & 12 & $\begin{array}{l}\text { Three types of trials of working memory } \\
\text { tasks (list of words): manipulation, } \\
\text { monitoring, and recognition control * }\end{array}$ & Recognition tasks vs. Monitoring \\
\hline 4. Christoff k. (2009) & fMRI & 16 & $\begin{array}{l}\text { Visual reasoning abstract problem tasks } \\
\text { with three degrees of difficulty* }\end{array}$ & Highly abstract vs. Moderately concrete \\
\hline 5. Eslinger P.J. (2009) & fMRI & 16 & Visuospatial relational reasoning problems* & $\begin{array}{l}\text { Recognition of color and shape vs. } \\
\text { Recognition of color }\end{array}$ \\
\hline 6. Bonner-Jackson A. (2008) & fMRI & 15 & $\begin{array}{l}\text { Two encoding task (Incidental and } \\
\text { intentional encoding) * }\end{array}$ & Intentional encoding vs. Incidental encoding \\
\hline 7. Bleich-Cohen M. (2009) & fMRI & 17 & $\begin{array}{l}\text { Language tasks of verb generation and } \\
\text { passive music listening* }\end{array}$ & Verb generation vs. Music hearing \\
\hline 8. Barbalat G. (2009) & fMRI & 14 & Series of successive colored letters* & $\begin{array}{l}\text { Consonant/vowel letter judgment vs. Lower- } \\
\text { /upper-case }\end{array}$ \\
\hline 9. Camchong J. (2008) & fMRI & 14 & $\begin{array}{l}\text { Abnormalities on antisaccade and ocular } \\
\text { motor delayed response (ODR) tasks* }\end{array}$ & Ocular motor delayed response vs. Fixation \\
\hline 10. Anilkumar A. P.P. (2008) & fMRI & 13 & Face encoding and recognition paradigm* & $\begin{array}{l}\text { Recognition of real faces vs. Darker image } \\
\text { identification }\end{array}$ \\
\hline 11. Fusar-Poli P. (2010) & fMRI & 15 & Visuospatial working memory task* & Hard vs. Intermediate level of difficulty \\
\hline 12. Broome M.R. (2009) & fMRI & 15 & $\begin{array}{l}\text { Object-location memory task with } \\
\text { manipulation of the mnemonic load* }\end{array}$ & Hard vs. Intermediate level of difficulty \\
\hline 13. Hirano Y.(2008) & fMRI & 33 & N- back & N-back vs. Zero-back \\
\hline 14. Karlsgodt K.H.(2009) & fMRI & 18 & Sternberg-style item recognition task & $\begin{array}{l}\text { Higher memory load trial vs. Lower memory } \\
\text { load trial }\end{array}$ \\
\hline
\end{tabular}




\begin{tabular}{|c|c|c|c|c|}
\hline 15. Kirschen M.P.(2010) & fMRI & 16 & Sternberg task & $\begin{array}{l}\text { Higher working memory load vs. Lower } \\
\text { working memory load }\end{array}$ \\
\hline 16. Landau S.M. (2009) & fMRI/PET & 23 & $\begin{array}{l}\text { Salthouse and Babcock listening Span } \\
\text { task/Sternberg }\end{array}$ & High load trials vs. Low-load trials \\
\hline 17. Leshikar E.D.(2009) & fMRI & 37 & Associative encoding task* & $\begin{array}{l}\text { Distinction between unrelated/related } \\
\text { objects vs. Objects that are categorically } \\
\text { related }\end{array}$ \\
\hline 18. Lewandowska M. (2010) & fMRI & 17 & Temporal-order- judgement (TOJ) task * & Long/short noises vs. Only long noises \\
\hline 19. Li J. (2009) & fMRI & 12 & Four types of face-detection stimuli* & $\begin{array}{l}\text { Detection of face images overlaid with more } \\
75 \% \text { of noise vs. Detection of face images } \\
\text { overlaid with } 5 \% \text { noise }\end{array}$ \\
\hline 20. Mathis A. (2009) & fMRI & 36 & Stroop task & $\begin{array}{l}\text { Incongruent word color-matched vs. } \\
\text { Congruent word-color }\end{array}$ \\
\hline 21. Nyberg L. (2009) & fMRI & 33 & N-back & N-back vs. Zero-back \\
\hline 22. O'Hare E.D. (2008) & fMRI & 30 & Verbal Sternberg task & High WM load vs. Medium WM load \\
\hline 23. Reynolds J.R. (2009) & fMRI & 18 & N-back & N-back vs. Zero-back \\
\hline 24. Rubia K. (2010) & fMRI & 63 & Oddball task & Longer vs. Shorter intervals of stimuli \\
\hline 25. Sharp D.J. (2010) & fMRI & 12 & $\begin{array}{l}\text { Semantic, acoustic \& phonological } \\
\text { processing difficulty task* }\end{array}$ & $\begin{array}{l}\text { Higher vs. Lower level of semantic, acoustic } \\
\text { or phonological stimuli }\end{array}$ \\
\hline 26. Silk T.J. (2010) & fMRI & 20 & $\begin{array}{l}\text { Working memory task, \& a visual search } \\
\text { task during the retention interval* }\end{array}$ & $\begin{array}{l}\text { A dual-task condition vs. Working memory } \\
\text { task alone }\end{array}$ \\
\hline 27. Specht K. (2009) & fMRI & 14 & Wisconsin Card Sorting Test & Color, symbol, or position vs. Baseline \\
\hline 28. Takahama S.(2010) & fMRI & 13 & Visual stimuli task of Saiki - modified* & $\begin{array}{l}\text { Stationary and moving tasks: binding trials } \\
\text { vs. Feature }\end{array}$ \\
\hline
\end{tabular}




\begin{tabular}{|c|c|c|c|c|}
\hline 29. Thompson, R. (2009) & fMRI & 31 & $\begin{array}{l}\text { Delayed matching task with color or shape } \\
\text { variation of stimuli* }\end{array}$ & $\begin{array}{l}\text { Hard vs. easy levels of difficulty of attended } \\
\text { dimension color or shape stimuli }\end{array}$ \\
\hline 30. Toepper M.(2010) & fMRI & 20 & CBT and BST & Encoding phase vs. baseline condition \\
\hline 31. Kim J. (2010). & fMRI & 13 & $\begin{array}{l}\text { Phonological delayed-matching-to-sample } \\
\text { task using an event-related design* }\end{array}$ & Correct vs. Error trials \\
\hline 32. Jamadar S.(2010) & fMRI & 12 & $\begin{array}{l}\text { Temporal and spatial dynamics of task- } \\
\text { switching }\end{array}$ & Incongruent stimuli vs. Congruent stimuli \\
\hline 33. Henseler I. (2009) & fMRI & 12 & $\begin{array}{l}\text { Variants of verbal and visuospatial of DMTS } \\
*\end{array}$ & $\begin{array}{l}\text { Alternating blocks vs. Geometric-form } \\
\text { judgment task }\end{array}$ \\
\hline 34. Choi J.W. (2008) & fMRI & 10 & Short/Long-term latency Stroop task & $\begin{array}{l}\text { Incongruent / Congruent conditions with } \\
\text { longer vs. Shorter latency }\end{array}$ \\
\hline 35. Borofsky L. A.(2010) & fMRI & 14 & Semantic judgment task* & Semantic vs. Syntactic condition \\
\hline 36. Crossley N.A. (2009) & fMRI & 13 & N-back & N-back vs. Zero-back \\
\hline 37. Green M.F.(2009) & fMRI & 19 & Backward masking task* & $\begin{array}{l}\text { Visual backward masking } \\
\text { task vs. Localizer tasks }\end{array}$ \\
\hline 38. Hashimoto R. (2010) & fMRI & 14 & $\begin{array}{l}\text { Auditory and visual verbal working memory } \\
\text { tasks* }\end{array}$ & $\begin{array}{l}\text { Encoding vs. Retrieval of auditory/Visual } \\
\text { tasks }\end{array}$ \\
\hline 39. Koch K. (2010) & fMRI & 20 & A modified gambling paradigm* & $\begin{array}{l}\text { Highly uncertain condition vs. Full prediction } \\
\text { condition }\end{array}$ \\
\hline 40. Luck D. (2010) & fMRI & 17 & Working Memory binding task* & Separate condition vs. Bound condition \\
\hline 41. Van Veelen N.M.J.(2010) & fMRI & 16 & Modified Stenberg memory task* & Novel task blocks vs. Practiced tasks blocks \\
\hline 42. Scheuerecker J.(2009) & fMRI & 23 & N-back & N-back vs. zero-back \\
\hline 43. Schlösser R.G.M. (2008) & fMRI & 41 & Modified Stenberg task & Forward condition vs. Alphabetize condition \\
\hline 44. Vinogradov S.(2008) & fMRI & 8 & $\begin{array}{l}\text { Implicit encoding + memory retrieval tasks } \\
\text { adapted from Vinogradov et al* }\end{array}$ & $\begin{array}{l}\text { Recognition of new words vs. Familiar } \\
\text { words }\end{array}$ \\
\hline 45. Hampshire A. (2009) & fMRI & 14 & Attentional load and target frequency & $\begin{array}{l}\text { Face/building stimuli vs. Face stimulus } \\
\text { alone. }\end{array}$ \\
\hline
\end{tabular}




\begin{tabular}{|lllll|}
\hline 46. Forn C. (2008) & fMRI & 14 & PASAT task & Covert responses vs. Overt responses \\
& & & N-back & N-back vs. Zero-back \\
47. Waiter G.D.(2009) & fMRI & 37 & Modified Digit Symbol Test task* & DMST task vs. Control task \\
48. Usui N.(2009) & fMRI & 11 & N-back & N-back vs. Zero-back \\
49. Vuontela V. (2009) & fMRI & 9 & Delayed item-recognition task* & Organization condition vs. Lower load \\
50. Wendelken C. (2008) & fMRI & 30 & Modified Color Stroop* & Incongruent vs. congruent condition \\
51. Ungar L. (2010) & fMRI & 15 & $\begin{array}{l}\text { Modified version of the Sternberg paradigm } \\
\text { (STERN) * }\end{array}$ & Novel vs. Practiced task \\
52. Van Raalten T.R.(2008) & $\mathrm{fMRI}$ & 18 & The diotic listening task & Incongruent selective condition vs. \\
53. Ikeda Y. (2010) & $\mathrm{fMRI}$ & 20 & Working memory binding task* & Congruent selective condition \\
& $\mathrm{fMRI}$ & 17 & & Separate vs. bounded conditions \\
54. Luck D. (2010) & & & \\
\hline
\end{tabular}

* Experimental Tasks specifically designed for the study. SWM: Spatial working memory

VWM: Verbal working memory

ODR: Ocular motor delayed response

TOJ: Temporal-order- judgement

CBT: Corsi Block-Tapping test

BST: Baseline condition of Corsi Block-Tapping test

PASAT: Paced Auditory Serial Addition test

DMTS delayed matching to sample task 
Table 3. Brain regions engaged both in time perception tasks and during tasks requiring cognitive effort.

\begin{tabular}{|c|c|c|c|c|c|}
\hline & \multicolumn{3}{|l|}{ Peak } & \multicolumn{2}{|l|}{ Cluster } \\
\hline & Talairach & Union & $P$ & Voxels & Breakdown \\
\hline$\frac{\text { Right parietal }}{\text { (inferior }>\text { precuneus }>\text { superior) }}$ & $38,-44,40$ & 0.004 & 0.000008 & 1069 & $\begin{array}{l}\text { Right BA } 40(566) \\
\text { Right BA } 7(349) \\
\text { Right BA } 19(87) \\
\text { Right BA } 39(67)\end{array}$ \\
\hline $\begin{array}{l}\text { Bilateral frontal } \\
\text { (middle > precentral }>\text { superior }> \\
\text { inferior }>\text { medial; extending to } \\
\text { cingulate gyrus, insula and basal } \\
\text { ganglia) }\end{array}$ & $-48,2,46$ & 0.008 & 0.00003 & 5001 & $\begin{array}{c}\text { Bilateral BA } 6(2577) \\
\text { Bilateral BA } 9(751) \\
\text { Bilateral BA } 8(312) \\
\text { Bilateral BA } 32(265) \\
\text { Bilateral BA } 13(185) \\
\text { Bilateral BA } 24(162) \\
\text { Bilateral BA } 44(144) \\
\text { Bilateral BA } 47(121) \\
\text { Bilateral BA } 45(116) \\
\text { Bilateral BA } 46(112) \\
\text { Right BA } 10(64) \\
\text { Left BA } 4(62) \\
\text { Bilateral claustrum (56) } \\
\text { Right putamen (54) }\end{array}$ \\
\hline$\frac{\text { Left parietal }}{\text { (inferior }>\text { precuneus }>\text { superior) }}$ & $-38,-46,48$ & 0.024 & 0.0003 & 1514 & $\begin{array}{l}\text { Left BA } 7(704) \\
\text { Left BA } 40(620) \\
\text { Left BA } 19(103) \\
\text { Left BA } 39(73) \\
\text { Left BA } 5(12)\end{array}$ \\
\hline
\end{tabular}

Threshold: voxel $p<0.01$, peak $p<0.001$, cluster extent $\geq 10$ voxels. Breakdown regions with less than 10 voxels are not reported. 
Table 4. Breakdown of the overlap and lack of overlap between brain regions engaged during time perception tasks and during tasks requiring cognitive effort.

\begin{tabular}{|c|c|c|c|}
\hline \multirow{3}{*}{ Regions mostly overlapping: } & \multicolumn{3}{|c|}{ Number of statistically significant voxels } \\
\hline & \multirow{2}{*}{$\begin{array}{c}\text { Only in time } \\
\text { perception (ALE) }\end{array}$} & \multirow[t]{2}{*}{$\begin{array}{c}\text { Only in cognitive } \\
\text { effort (SDM) }\end{array}$} & \multirow[t]{2}{*}{$\begin{array}{c}\text { In both types } \\
\text { of tasks }\end{array}$} \\
\hline & & & \\
\hline Precentral cortex & 760 & 601 & 5,527 \\
\hline Inferior frontal cortex & 1,383 & 2,438 & 3,772 \\
\hline Supplementary motor area & 1,001 & - & 3,636 \\
\hline Middle frontal cortex & 448 & 1,636 & 3,332 \\
\hline Inferior parietal cortex & 221 & 422 & 3,191 \\
\hline Superior parietal cortex & - & 1,213 & 2,630 \\
\hline Superior frontal cortex & 306 & 370 & 2,548 \\
\hline Postcentral cortex & 488 & 420 & 1,690 \\
\hline Angular gyrus & 139 & 360 & 1,515 \\
\hline Insula & 690 & - & 1,336 \\
\hline Precuneus & 199 & 450 & 1,095 \\
\hline Middle cingulum & - & 264 & 914 \\
\hline Superior occipital cortex & - & 591 & 739 \\
\hline Supramarginal gyrus & 205 & - & 434 \\
\hline \multicolumn{4}{|c|}{ Regions mainly involved in time perception: } \\
\hline Putamen & 1,213 & - & 532 \\
\hline Caudate & 967 & - & - \\
\hline Middle temporal cortex & 668 & - & - \\
\hline Superior temporal cortex & 539 & - & - \\
\hline Pallidum & 400 & - & - \\
\hline Rolandic operculum & 387 & - & 252 \\
\hline Paracentral lobule & 247 & - & - \\
\hline Temporal pole & 145 & - & - \\
\hline \multicolumn{4}{|c|}{ Regions mainly involved in cognitive effort: } \\
\hline Cerebellum & 733 & 6,216 & - \\
\hline Middle occipital cortex & - & 1,517 & 439 \\
\hline Fusiform gyrus & - & 960 & - \\
\hline Thalamus & 258 & 941 & - \\
\hline Inferior temporal cortex & - & 617 & - \\
\hline Cuneus & - & 339 & 265 \\
\hline Calcarine gyrus & - & 331 & - \\
\hline Inferior occipital cortex & - & 122 & - \\
\hline
\end{tabular}

Labels according to the AAL atlas after conversion to $\mathrm{MNI}$ space; regions comprising less than 100 voxels not shown. 


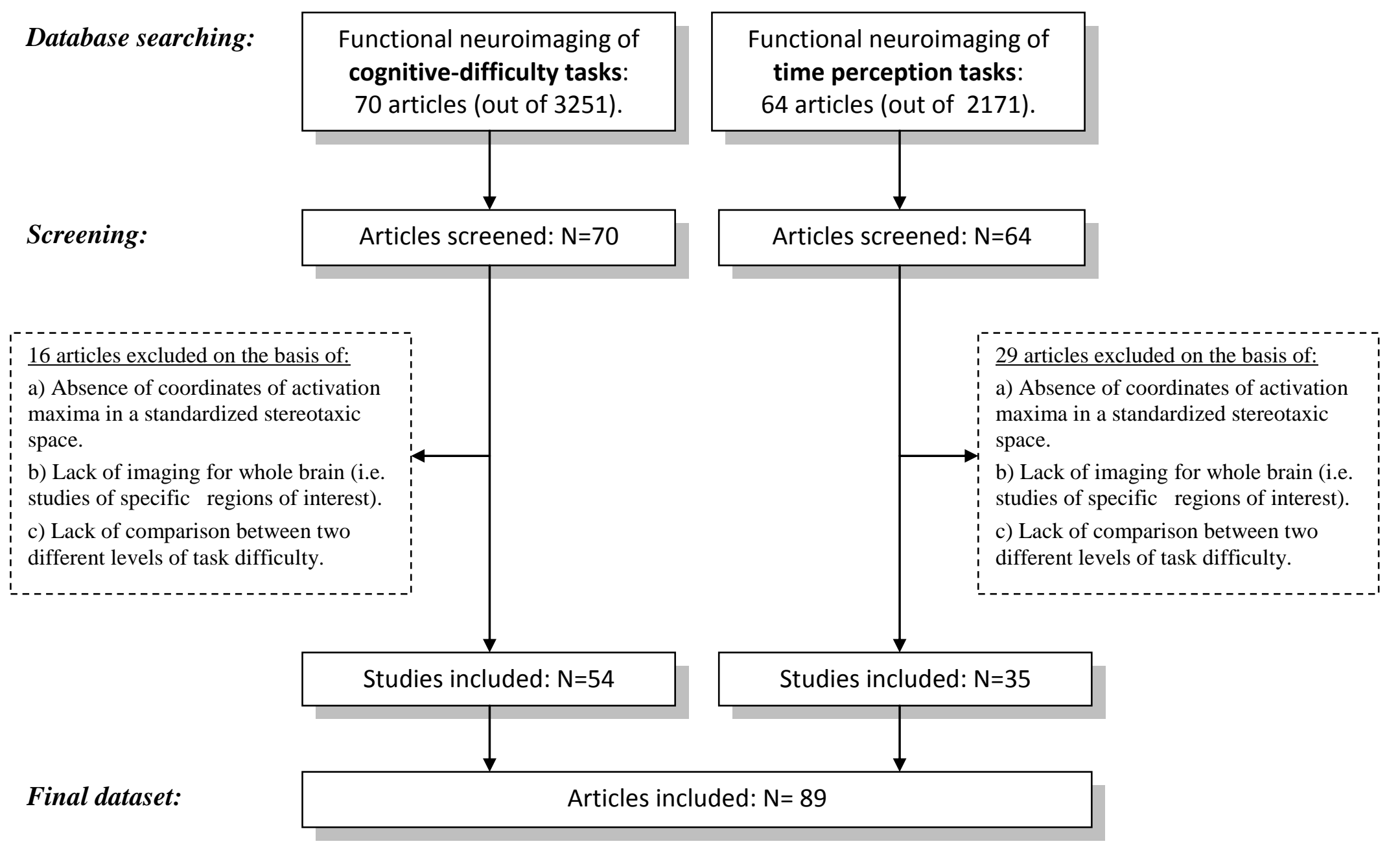




\section{Figure}

Click here to download high resolution image

\section{Medial view:}

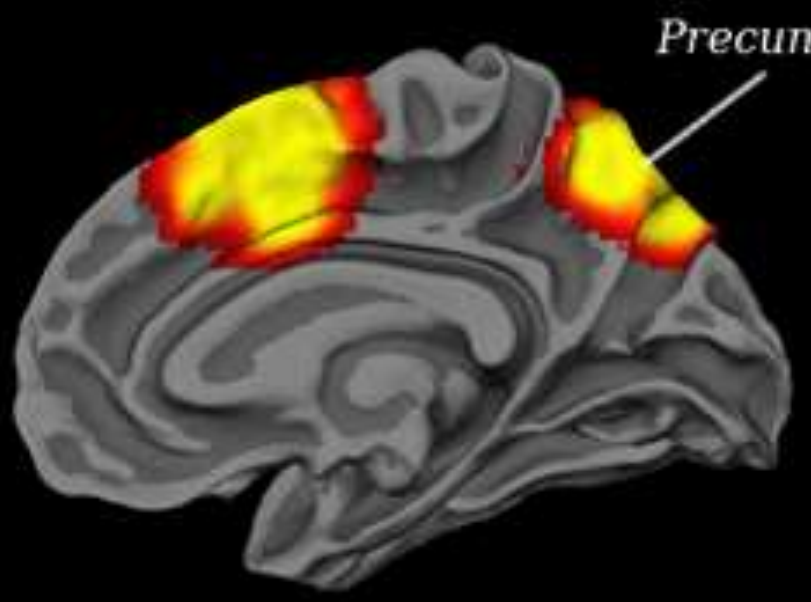

Supplementary motor area

\section{Lateral view:}
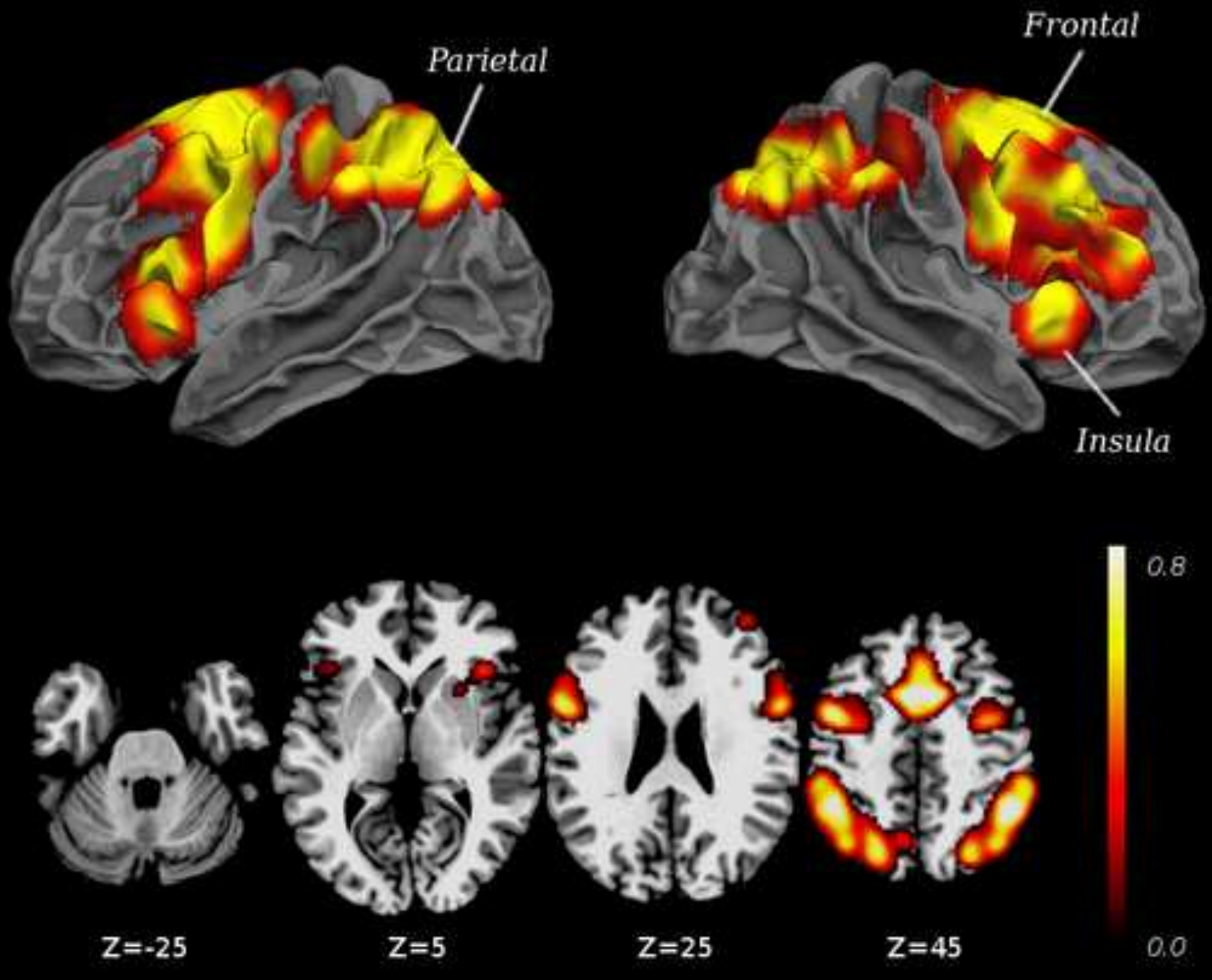


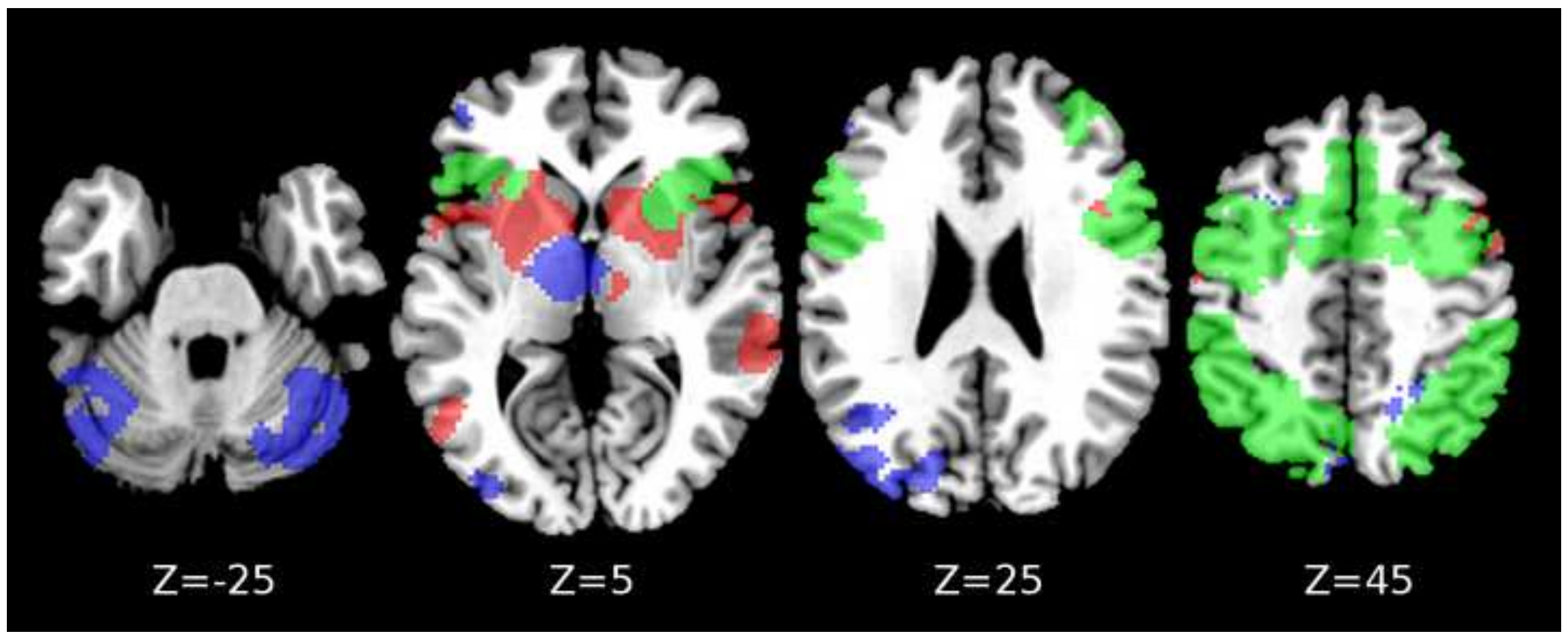

\section{Click here to download high resolution image}




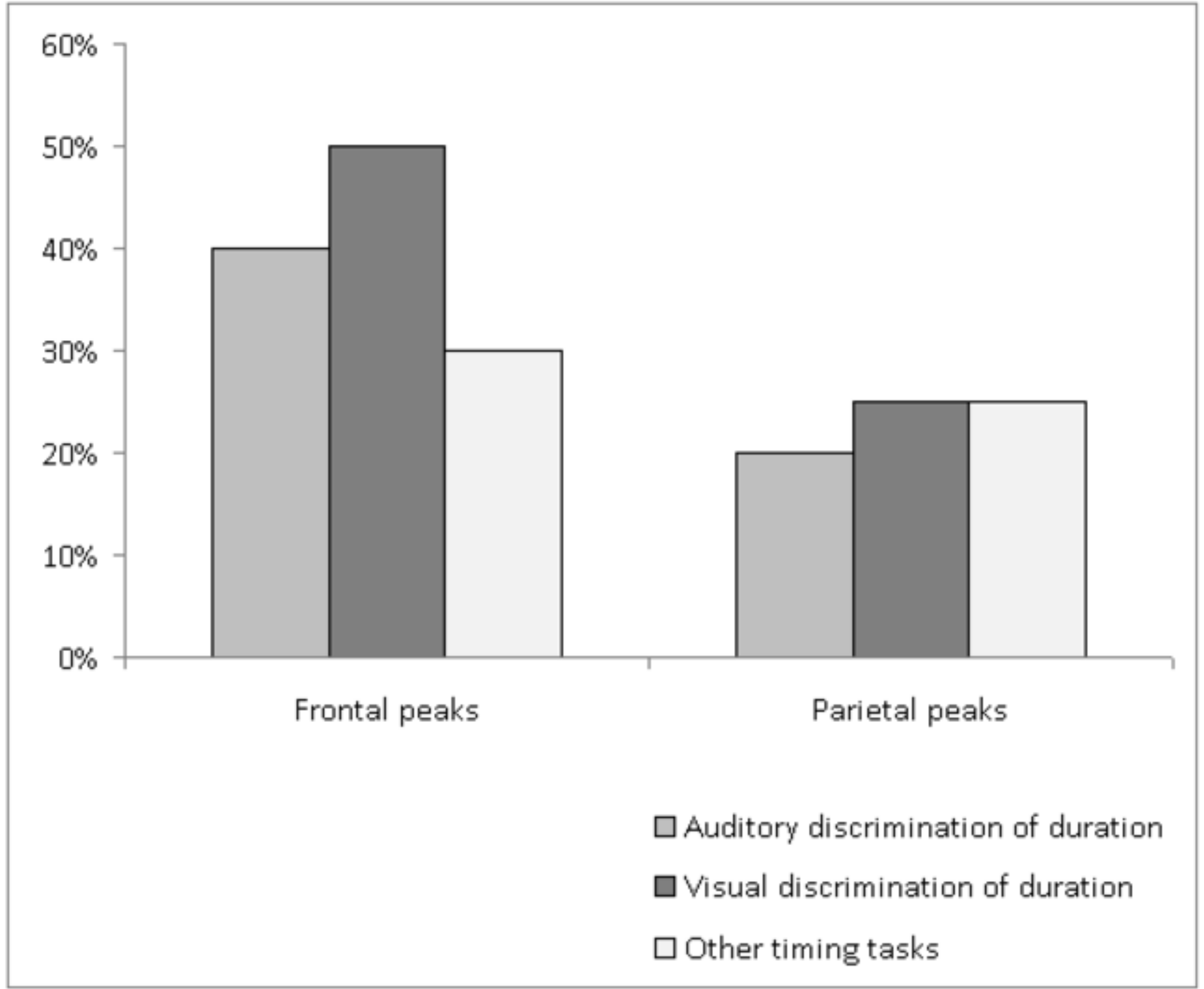


Supplementary Material
Click here to download Supplementary Material: Supplementary data. Table of Studies included in Ortuno et al time perception

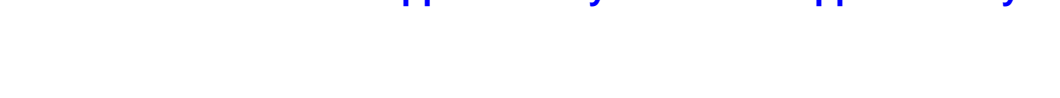
(n) perstion ir

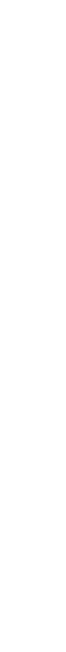

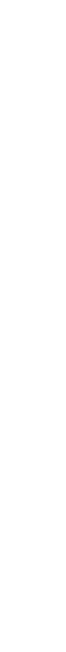

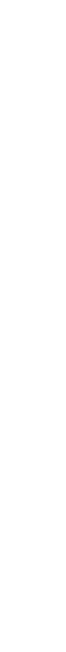

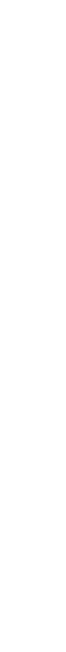

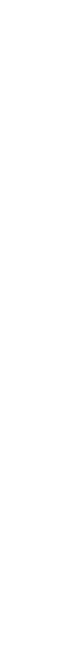

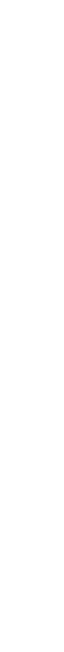

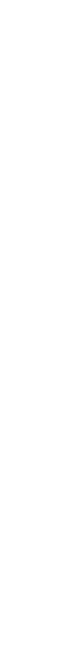

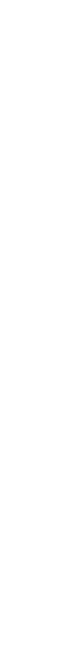
(1) (1) 